\title{
Experimental study of force generated by orthodontic niti archwires from different manufacturers
}

\begin{abstract}
An experimental study was undertaken to research physical properties of orthodontic wires from five manufacturers. Archwires, especially NiTi wires, of the same cross-section, size and alloy acronym, but from various manufacturers, produce different forces under the same conditions
\end{abstract}

Keywords: physical properties of orthodontic nickel-titanium wires, orthodontic appliances
Volume 5 Issue 7 - 2016

\author{
Vasilyeva MB, Kosyreva TF \\ Department of Pediatric Dentistry and Orthodontics, People's \\ Friendship University of Russia, Russia
}

\begin{abstract}
Correspondence: Maria Vasilyeva, Department of Pediatric Dentistry and Orthodontics, People's Friendship University of Russia, Micklucho-Maklaya str, I0, bilding 2, Medical Unstitute, PFUR, Moscow, II7I98, Russia, Tel 7 (916) 687-93-34, Email dr.vasilyeva003@gmail.com
\end{abstract}

Received: December 22, 2015 | Published: December 28, 2016

\section{Significance}

Patient treatment with orthodontic appliances suggests solving the complicated biomechanical, biophysical, technological problems. Implementation of any orthodontic treatment technique should be preceded by a scrupulous biomechanical analysis of the construction in use. Force intensity and direction depend on appliance design and type of movement chosen by doctor. Reasonable application of biomechanical conceptions contributes to increase of treatment success. ${ }^{1-3}$ Integration of different dental specialists has recently widely developed and interdisciplinary communication has improved. Dentists of different specialties cooperate with specialists in biomechanics, theoretical mechanics, etc., to give comprehensive solution to patient's problems and develop an optimal treatment plan. Modern orthodontics also needs research and results in related fields of science (physics, mechanics, mathematics, etc.). Forces applied to a tooth (or a dental arch) and type of movement manifests themselves through a ratio moment/ force developed by an orthodontic appliance. Properties of an orthodontic straight arch wire are paramount in bracket/arch wire system. Orthodontic market offers a large variety of archwires of different alloys. And we experimentally found out that wires, especially nickel-titanium (NiTi) wires of the same crosssection, size and alloy but from different manufacturers deliver different forces under the same conditions.

\section{Materials and methods}

Deformation of pieces of straight round NiTi wires was studied in the experiment. The study was undertaken in the laboratory of coherent photoelastic methods of stress and deformation analysis at the Department of Physics of Strength, National Nuclear Research University, under the leadership of associate professor A.V. Osintsev, $\mathrm{PhD}$ in Technical Sciences. Load intensity (compression force) generated by deflection (deformation) of a straight NiTi wire piece into a loop was measured with a device, developed by ourselves, which consisted of a highly accurate digital force gauge (capacity up to $500 \mathrm{~g}$ and load measurement precision- $0.1 \mathrm{~g}$ ) and a micrometer screw with precision of movement measurement-10 $\mu \mathrm{m}$. Compression force was studied in relation to width of loop recovery under loading and unloading of three NiTi wire pieces of different length. Dimensions and loading pattern of a NiTi wire piece are shown in Figure 1. The study investigated physical properties of standard orthodontic NiTi wires from the following manufacturers: $3 \mathrm{M}$ (Germany), Forte (UK), Proflex (USA), G+H (GAC) (USA), ORMCO (USA). The following sizes of round NiTi wires were used: 0.014 inch, 0.016 inch, 0.018 inch. Pieces of straight NiTi wires $(23 \mathrm{~mm}, 28 \mathrm{~mm}$ and $35 \mathrm{~mm})$ were selected empirically providing for use of double archwire or their separate element mechanics. Three most relevant sizes of these archwire pieces (L1) were used to record forces: $23 \mathrm{~mm}, 28 \mathrm{~mm}$ and $35 \mathrm{~mm}$, and also three sizes of loop width during the process of compression of an archwire piece (L2): $7 \mathrm{~mm}, 9 \mathrm{~mm}$ and $11 \mathrm{~mm}$. To increase the accuracy of measurements, all measurements were taken on three pieces of identical archwires from the same delivery lot. In total there were made 90 investigations of different NiTi wires and their loops. At the beginning the load for each wire piece was respectively recorded at $11 \mathrm{~mm}$, the loop width was decreased to 9 $\mathrm{mm}$ with a micrometer screw and the load was measured. After that approximation was set at $7 \mathrm{~mm}$ and load was recorded. In this position the wire compressed and the loop lengthened with load increase. Then the loop width was enlarged to $9 \mathrm{~mm}$ and the load was measured. Then the approximation was increased to $11 \mathrm{~mm}$ and respective load was recorded. There was an unloading, loop recovery as an active loop and returning to its original state. There were 5 points of measurements. So, 675 measurements were taken on 135 patterns of wire pieces: 5 materials, 3 sizes of cross-section, 3 lengths of wire pieces and 3 patterns of the same size cross-section, material and length wire pieces (to check repeatability of results). Comparison of load intensity in different types of slot closing was done according to formulas of mathematical simulation. 

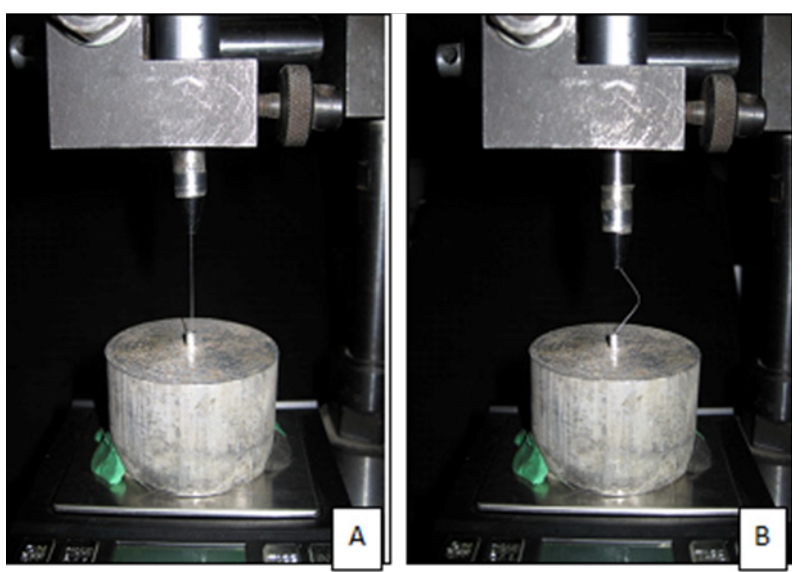

Figure I The device for loading piece $\mathrm{NiTi}$ wire and measurement of efforts of compression and a relaxation: in an initial condition-A, loaded-B.

\section{Results}

Figure 2 presents dependency diagrams of compression force magnitude (in g) generated by NiTi wire pieces, $23 \mathrm{~mm}$ long, from 5 manufacturers vs. loop recovery intensity (in $\mathrm{mm}$ ). Dependency diagrams of compression force magnitude (in g) generated by NiTi wire pieces (28mm long) from 5 manufacturers against loop recovery intensity (in $\mathrm{mm}$ ) are shown in Figure 3. Analyzing received experimental data, shown in (Figure 2) (Figure 4), it is possible to see some patterns:

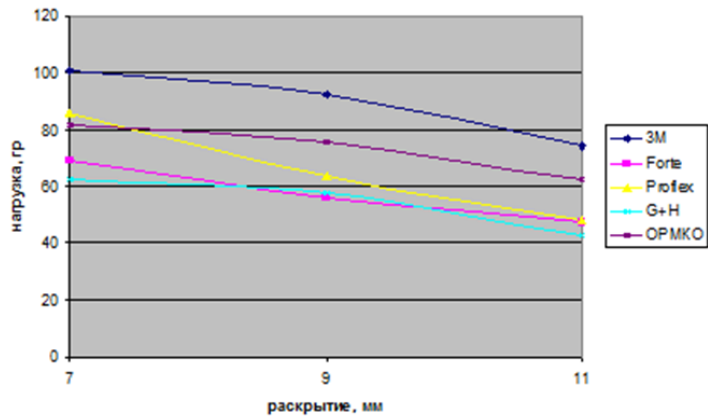

Figure 2 Dependency diagrams of compression force magnitude of a wire piece against intensity of loop recovery, from 7 to $1 \mathrm{Imm}$, for the studied 0.014 0.016 and 0.018 -inch $\mathrm{NiTi}$ wires, originally $23 \mathrm{~mm}$ long, from 5 manufacturers.

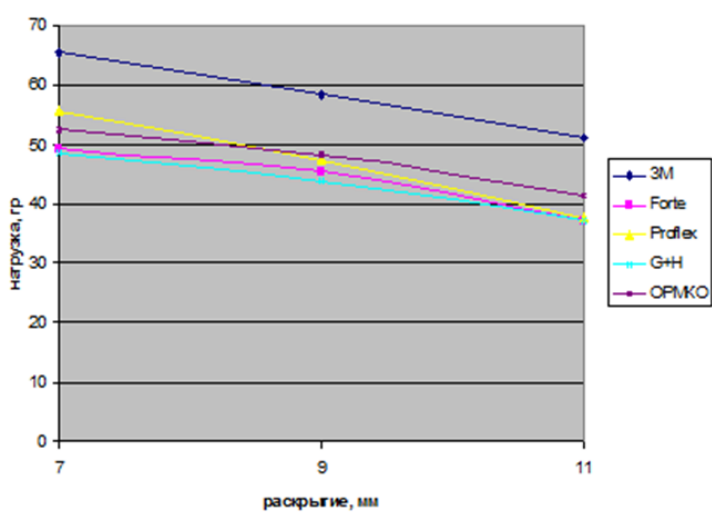

Figure 3 Dependency diagrams of compression force magnitude of a wire piece against intensity of loop recovery, from 7 to $1 \mathrm{Imm}$, for the studied 0.014 , 0.016 and 0.018 -inch NiTi wires, originally $28 \mathrm{~mm}$ long, from 5 manufacturers.

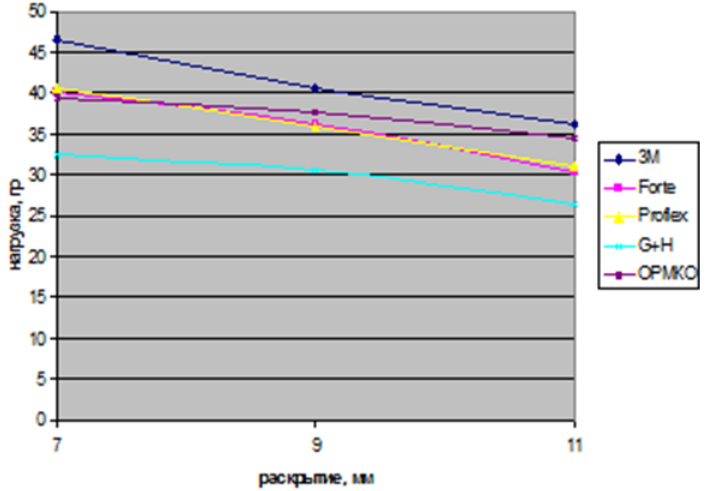

Figure 4 Depicts dependency diagrams of compression force magnitude generated by NiTi wire pieces ( $35 \mathrm{~mm}$ long) from 5 manufacturers against loop recovery intensity. 0.018 - wires, originally $35 \mathrm{~mm}$ long, from 5 manufacturers.

a. Force magnitude depends on the length of the wire piece for the straight NiTi wire pieces made from orthodontic wires of one manufacturer with the same intensity of deflected loop recovery and cross-section geometry. If the wire is shorter and loop recovery intensity remains the same, the force generated by the loop increase. So, the smaller the intra-bracket distance is, or the more severe the crowding is, the higher the load created by the wire is.

b. Force magnitude depends on type of loading for NiTi wire pieces from one manufacturer of the same length, cross-section geometry and recovery intensity. The force is higher under loading than unloading. So, compression force decreases in proportion to alignment.

c. Magnitude of force depends on the wire material (quality of $\mathrm{Ni}-\mathrm{Ti}$ alloy) used by the manufacturer for NiTi wire pieces of the same size and cross-section geometry, length of piece and loop recovery intensity. Under deflection or loading of $3 \mathrm{M}$ wire (Germany), same size loops will generate greater load than identical loops of wires produced by ORMCO (USA), Proflex (USA), Forte (UK), GAC (USA).

Thus, 0.016-inch Ni-Ti wire piece from 3M (Germany) produces a force of $101.1 \mathrm{~g}$ what means $15-30 \%$ higher compression force than generated by wire pieces from other manufacturers $(62.5-85.5 \%)$. $3 \mathrm{M}$ NiTi archwires develop sufficient force for bodily (100-150g) or tipped $(75-125 \mathrm{~g})$ movement of posterior teeth. At the same time 0.016-inch NiTi wires from Proflex (USA), ORMCO (USA) and also 0.014 -inch NiTi wires from $3 \mathrm{M}$ produce the most physiological forces for rotation and extrusion of teeth $(50-75 \mathrm{~g})$. 0.014-inch NiTi wires from GAC (USA) develop the most physiological force for teeth intrusion $(25-30 \mathrm{~g})$. Therefore, taking into account this data, at the leveling stage it is possible to use NiTi wires from a relevant manufacturer, decreasing or increasing wire cross-section diameter according to the task. Experimental data was averaged over three patterns. Dependency diagrams of compression forces on a NiTi wire piece under loading and unloading are shown in Figure 5. Force magnitude decrease is noted under wire unloading. Besides 3M NiTi orthodontic wire shows more constant load $(132 \mathrm{~g})$ of teeth with loss of force-20.4\% $(\mathrm{P}<0.001)$. When recording the forces generated in $\mathrm{NiTi}$ wires pieces, we found out force relaxation phenomenon, i.e. decrease of load intensity over time. This process was studied on 6 round 0.016 -inch NiTi wire pieces $(5 \mathrm{NiTi}$ wires and $1 \mathrm{CuNiTi}$ wire 
with addition of copper) from the same 5 manufacturers. Pieces were $28 \mathrm{~mm}$ long and loop width was $9 \mathrm{~mm}$. The studied pieces were put in the loading device and width of loop $(=9 \mathrm{~mm})$ was set and the load at the initial time $(\mathrm{T}=0)$ was recorded. Then the load was measured after 1 hour, 2, 3, 4, 5, 6, 8, 12, 22, 24, 48 and 72 hours. The load decreased over time after the piece was fixed in the loading device. All measurements were taken on pieces of three identical wires from the same delivery lot to increase significance of experimental results. Figure 6 presents' dependency diagrams of force magnitude of 0.016inch NiTi and CuNiTi wire piece, $28 \mathrm{~mm}$ long, loaded as a loop, and recovery intensity of $9 \mathrm{~mm}$ loop vs. time, for six variants of wires (two materials and 5 manufacturers). Analyzing received experimental data it is worth mentioning that the load for the studied wires of the given manufacturers is almost stabilized after 24 hours and remains constant. After 12 hours of load, minimal decrease of magnitude of loop compression force is noted in the pieces of NiTi wires: $3 \mathrm{M}$ NiTi wire piece loop-22.9\%, Forte NiTi loop-25.3\%, Proflex NiTi loop$25.3 \%$, GAC NiTi loop-25.4\%, ORMCO-26.1\%, ORMCO CuNiTi loop-29.8\% (maximum). So, in 12 hours $3 \mathrm{M} \mathrm{NiTi}$ archwires show the least relaxation (decrease of force magnitude)- $22.9 \%$, in comparison with NiTi and CuNiTi wires of the same size from other manufacturers $(25-30 \%)(\mathrm{P}<0.001)$.

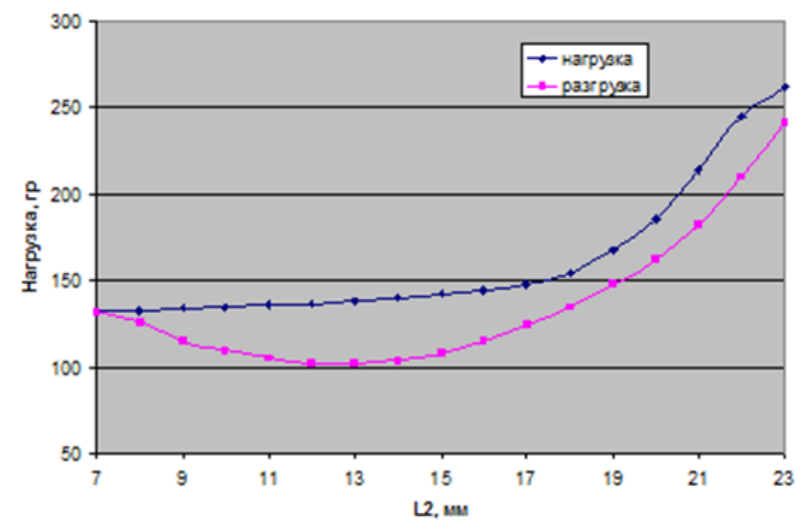

Figure 5 Dependency diagrams of force magnitude $\mathrm{P}$ of $3 \mathrm{M}$ 0.016-inch NiTi wire piece, $\mathrm{LI}=23 \mathrm{~mm}$, vs. L2 - loop recovery intensity.

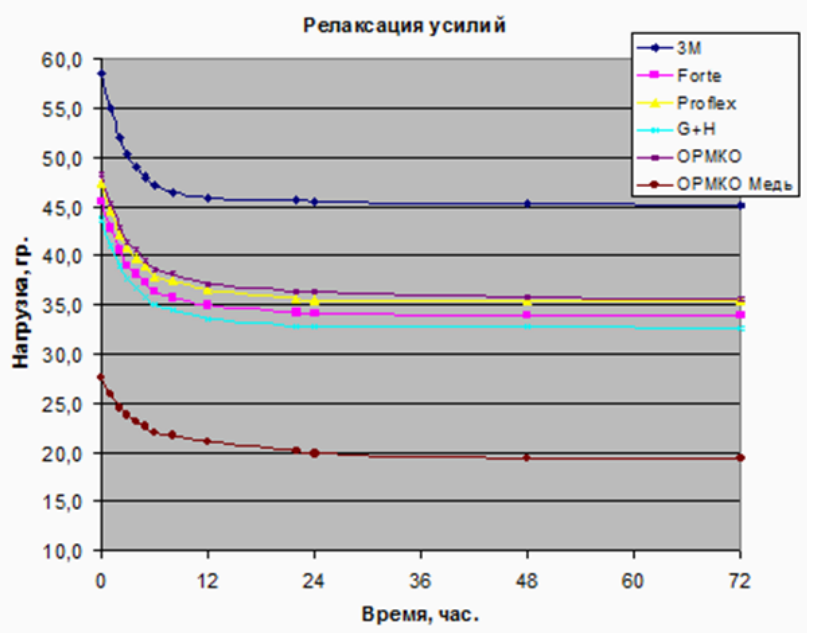

Figure 6 Dependency diagram of P-compression force magnitude of loops of $\mathrm{NiTi}$ and CuNiTi wire pieces, 9mm, 5 manufacturers, vs. L 2 - time (72 hours).

\section{Conclusion}

As you know that there are a lot of options of tooth movement. However, they can be conventionally divided into four main types: tipping, bodily movement, root movement and rotation. Each type of movement is a result of actions of different magnitude, direction or point of force application. ${ }^{1}$ Taking into consideration that recommended physiological load for bodily movement of molars will be $100-150 \mathrm{~g}$, in case of change of angulation (tipping) of molars it will be $85-100 \mathrm{~g}$, one should select wires with load intensity 25 $30 \%$ higher than recommended, taking into account load relaxation phenomenon. Thus, it is recommended to use 3M 0.016-inch NiTi archwire for bodily or tipped tooth movement at the leveling phase after the initial adaptive 0.012- or 0.014-inch NiTi or CuNiTi wire. 0.014-inch NiTi wire from 3M (Germany) and 0.016-inch NiTi wires from Proflex (USA) and ORMCO (USA) are recommended for extrusion and rotation of teeth. 0.014-inch NiTi wires from GAC (USA) develop the most physiological forces for tooth intrusion.

\section{Acknowledgments}

None.

Funding

None.

\section{Conflicts of interest}

The authors declare there is no conflict of interests.

\section{References}

1. Ravindra Nanda. Biomechanics and esthetic strategies in clinical orthodontics (0721601960). New York, USA: Saunders; 2005:1-400.

2. Prokofyev E, Gunderov D, Prokoshkin S, et al. Microstructure, mechanical and functional properties of NiTi alloys processed by ECAP technique. ESOMAT. 2009;6:1-5.

3. Meisner LL. Mechanical and physical and chemical properties of alloys based on nickel-titanium. Fiz.mezomeh. Sp Vyp-Ch2-S. 2004:169-172. 